\title{
la produckión de árido ligero hueco por precalentamiento controlado
}

\section{Introducción}

Los factores que causan el hinchamiento de las arcillas tratadas a altas temperaturas fueron sometidos a un estudio intenso durante los últimos quince años, particularmente en los Estados Unidos. Aun cuando los sistemas minerales en los que se incluyen los áridos ligeros son muy complejos, las investigaciones realizadas empleando los rayos $\mathrm{X}$, el análisis térmico diferencial y el análisis químico, así como la cromatografía de gases, permiten ahora valorar los materiales arcillosos respecto a su aptitud para producir un producto comercial; muchas de las reacciones que tienen lugar durante la dilatación son enteramente conocidas y, además, se han mejorado y modificado simultáneamente las téenicas de producción en escala industrial.

Aunque se han realizado considerables investigaciones sobre el papel que desempeña el carbono orgánico y se han observado sus efectos en pequeñas cantidades, todavía no se conocen bien las reacciones que tienen lugar con grandes contenidos de materia orgánica. Conley (1) llega a la conclusión de que el papel de la materia orgánica no está completamente claro; en ciertas arcillas parece no tener ningún efecto sobre el proceso de hinchamiento, mientras que en otras el efecto es considerable. Cuando se calienta suavemente una muestra arcillosa el carbono se quema entre $350^{\circ}$ y $980^{\circ} \mathrm{C}$, antes de que tenga lugar la vitrificación. Cuando se calienta rápidamente a $1.000^{\circ} \mathrm{C}$ o más, como se hace en la producción del árido ligero, la pérdida de carbón no es completa. Jackson (2) establece que la presencia de grandes cantidades de carbono a esas temperaturas ejerce un efecto retardador sobre la oxidación y eliminación del azufre y la oxidación del hierro.

Austín, Nunes y Sullivan (3) concluyen que el $\mathrm{CO}_{2}$ presente como agente que provoca el hinchamiento, procede de la reacción del carbono orgánico con el oxígeno, el cual procede, a su vez, de la reducción del óxido férrico. Ehlers (4) encontró que, aunque los minerales carbonatados y sulfurados son la principal fuente del hinchamiento, las partículas de carbón finamente dispersas en la masa suministran una fuente de gas. Lawrence (5), mediante un estudio sobre mezclas sintéticas, pudo demostrar que muchos materiales que, generalmente, se suponía que se descomponían a bajas temperaturas, realmente se consideran ser los causantes del hinchamiento durante el intervalo de fusión; éstos incluyen grafito, lignito y pirita.

En un estudio previo realizado por H. T. Stamboliev (6) con sesenta arcillas de Yugoslavia, una de las conclusiones a que llegó fue que las arcillas que contienen grandes cantidades de materia orgánica producen una estructura débil y deleznable en el árido. Este punto de vista coincide con el del mayor productor de áridos ligeros [ver Everhart (7)]. Entre estas arcillas había una que contenía grandes cantidades de materia orgánica, álcalis y sulfatos, que presentó un comportamiento singular al fuego. Teniendo en cuenta que este hecho aislado no tenía importancia económica, su estudio se aplazó para mejor ocasión.

\section{Materias primas, estado natural y composición}

El estudio de estas arcillas comenzó sobre una muestra de Manastir (Yugoslavia). Se presentan en capas de espesor variable dentro de un gran depósito de tierra de diatomeas. Los análisis de sedimentación con la pipeta de Andreasen (8) indicaron que el $99 \%$ de las partículas eran inferiores a $50 \mu$. El análisis por rayos $\mathrm{X}$, empleando un difractómetro Norelco de pequeño ángulo, con radiación de cobre, indicaba que los minerales arcillosos presentes eran illita y caolinita. La relación en que se encontraban éstos era 6 a 1, basándose en las técnicas de Murray (9).

La ausencia de montmorillonita y clorita se comprobó por un análisis adicional con rayos $\mathrm{X}$ en las regiones críticas después del tratamiento con etilenglicol y calentando la muestra a $566^{\circ} \mathrm{C}$. El análisis pretrográfico indicó la presencia de láminas de moscovita, cuarzo, diatomeas, oligoclasa, 
hornablenda y diversos óxidos de hierro hidratados. Se supuso la presencia de pirita, aunque no fuera revelada por los análisis petrográfico y rayos $\mathbf{X}$, por el hecho de que una gran proporción de la muestra tenía un peso específico superior a 3,32 (yoduro de metileno). El peso específico de los minerales areillosos era de 2,5, mientras que el de los sulfuros es mayor que 3,32. La arcilla de Manastir usada en este estudio se empleó de dos maneras: sin tratar y calentada entre $1.250^{\circ}$ y $1.300^{\circ} \mathrm{C}$ para crear los agentes de hinchamiento. El análisis químico se da en la tabla I. El pH del agua en contacto con la arcilla fue inferior a 6 . El azufre presente era del $1,48 \%$ en forma de sulfatos solubles en agua.

La segunda arcilla estudiada, después de conocer de antemano (10) sus propiedades dilatables, fue una arcilla de superficie de las cercanías de Orrville, de la comarca de Wayne (Ohio). Esta arcilla tiene una relación illita/caolinita de 2,6 y contiene abundante cuarzo, así como cantidades menores de microclina, óxido de hierro, calcita, pirita, moscovita y turmalina. Fue catalogada en el primer estudio con el número 37 , y sus propiedades normales de hinchamiento fueron descritas como sigue: Calentada bruscamente a 1.150 y $1.315^{\circ} \mathrm{C}$ se produce una vitrificación parcial; el gas que producía el hinchamiento estaba compuesto de $\mathrm{CO}_{2}$ y $\mathrm{SO}_{z}$, según indicaba el análisis cromatográfico. El gas se producía por descomposición de caicita y pirita. No se disponía del análisis químico. Esta arcilla de Orrville se empleó en este estudio con una adición de $6 \%$ de negro de humo y $0,4 \%$ de sulfato sódico, ya que los ensayos previos de calentamiento revelaron que la composición natural no porduciría una muestra dilatada con una gran cavidad central.

TABLA I._Análisis químico de la areilla de Manastir.

\begin{tabular}{lr} 
COMPONENTES & \multicolumn{1}{c}{$\%$} \\
\hline $\mathrm{SiO}_{2}$ & 50,53 \\
$\mathrm{Al}_{2} \mathrm{O}_{3}$ & 19,49 \\
$\mathrm{Fe}_{2} \mathrm{O}_{3}$ & 5,82 \\
$\mathrm{CaO}$ & 1,82 \\
$\mathrm{MgO}$ & 1,20 \\
$\mathrm{Na}_{2} \mathrm{O}$ & 1,14 \\
$\mathrm{~K}, \mathrm{O}$ & 2,09 \\
$\mathrm{~S}$ (total) & 1,87 \\
$\mathrm{C}$ & 4,76 \\
$\mathrm{H}$ & 1,09 \\
$\mathrm{Cl}$ & $<0,004$
\end{tabular}

\section{Técnica experimental}

Los nódulos esféricos preparados con las arcillas de Manastir y Orrville tenían diámetros de 6, 8,10 y $15 \mathrm{~mm}$. Se hicieron por extrusión de la arcilla húmeda en una galletera de laboratorio sin vacío. La columna obtenida se cortó en trocitos convenientes y transformados a mano en esferitas de los diámetros citados. La oscilación en los tamaños de los nódulos fue de $\pm 0,15 \mathrm{~mm}$, lo que se consideró como suficiente para dar como buenos los resultados experimentales. Los nódulos se secaron a $110^{\circ} \mathrm{C}$ y fueron calentados entre $270^{\circ}$ y $300^{\circ} \mathrm{C}$ durante algunos minutos antes del ulterior tratamiento; esto era necesario para prevenir la explosión cuando fueran sometidos bruscamente a las temperaturas de precalentamiento.

Seis nódulos de cada tipo y tamaño se precalentaron a $550^{\circ} \mathrm{C}$ en un pequeño horno eléctrico de laboratorio. Se establecieron los tiempos de precalentamiento de $15,30,60$ y 90 minutos para la mayoría de las muestras. Las muestras precalentadas fueron luego dilatadas por golpe de fuego en un horno Globar de laboratorio. Los nódulos se pusieron sobre una placa refractaria previamente recubierta con harina de sílice para evitar el pegado. Las condiciones óptimas de tiempo-temperatura para la dilatación se consideraron ser de 10 y 15 minutos a $1.270^{\circ} \mathrm{C}$ para la arcilla de Manastir y 15 minutos a $1.200^{\circ} \mathrm{C}$ para la de Orrville.

El peso específico de las muestras obtenidas se determinó por medio del volumenómetro en agua. Las muestras se pesaron, se recubrieron con una delgada capa de parafina y se volvieron a pesar antes de ponerlas en el volumenómetro. El volumen se determinó por desplazamiento del agua en una microbureta. Las determinaciones sucesivas sobre la misma muestra oscilaron entre 0,1 y $1 \%$, dependiendo del tamaño de los nódulos expandidos. La fórmula empleada para determinar el peso especffico fue:

$$
P_{c}=\frac{G_{s}}{V_{p s}-\frac{G_{p s}-G_{s}}{0,88}}
$$

Siendo: $\mathrm{G}_{s}=$ Peso de la muestra seca.

$\mathrm{G}_{p s}=$ Peso de la parafina que envuelve la muestra.

$\mathrm{v}_{p s}=$ Volumen de la parafina que envuelve la muestra.

$0,88=$ Peso específico de la parafina empleada. 


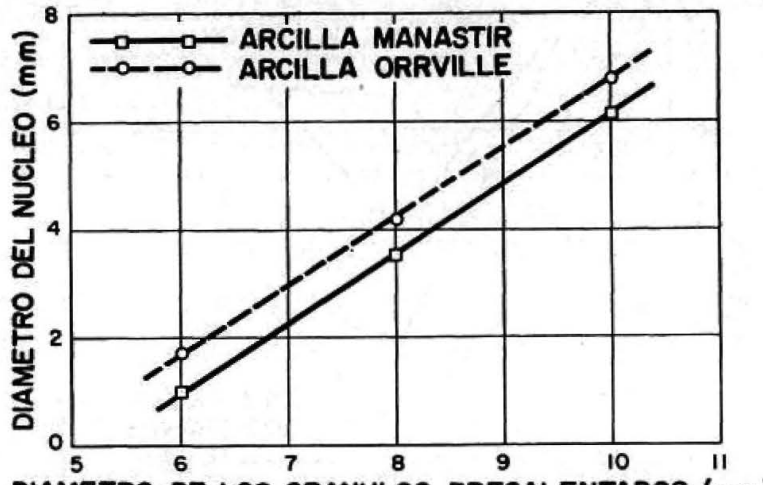

DIAMETRO DE LOS GRANULOS PRECALENTADOS (mm)

Fig. 1. Diámetro del núcleo rieo en carbón en función del diámetro total del gránulo.

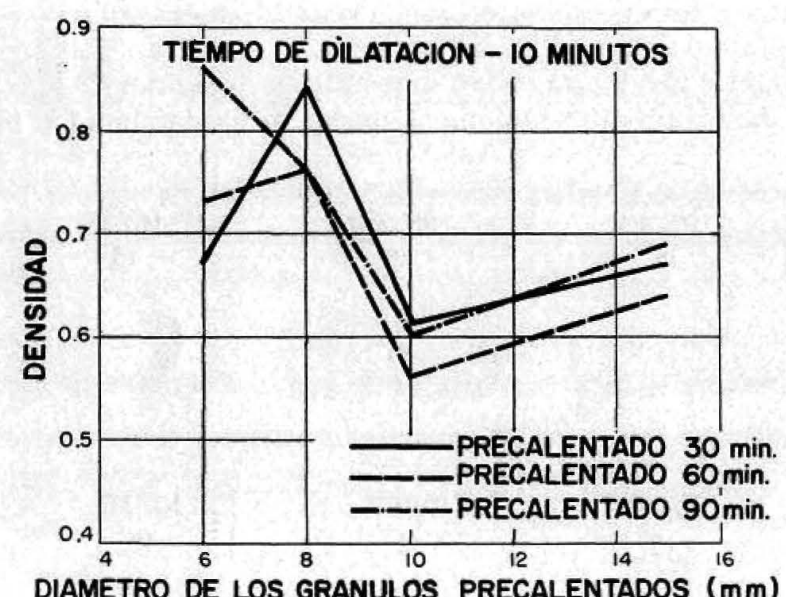

Fig. 3. Efecto del tiempo de precalentamiento en la densidad de gránulos de distintos tamaños sinterizados durante 10 minutos.

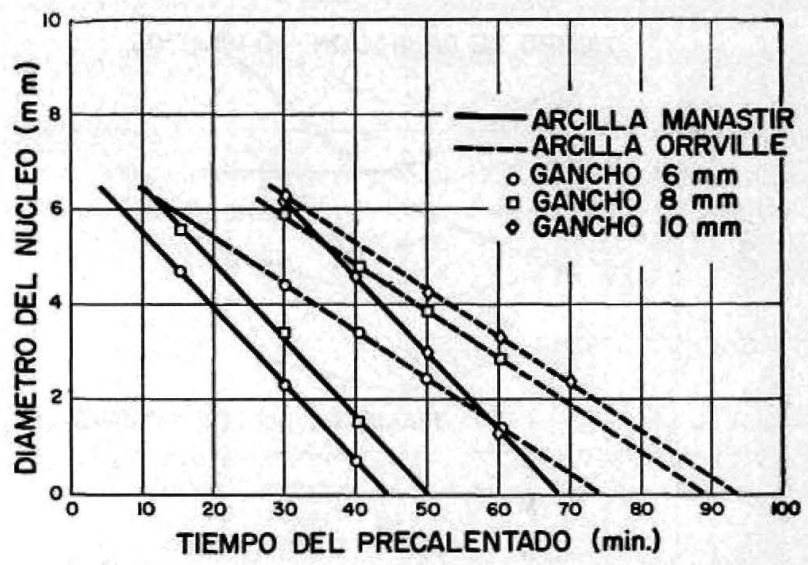

Fig. 2. Relación đel diámetro del núcleo ríco en carbón con el tiempo de precalentamiento para diferentes tamaños de gránulos.
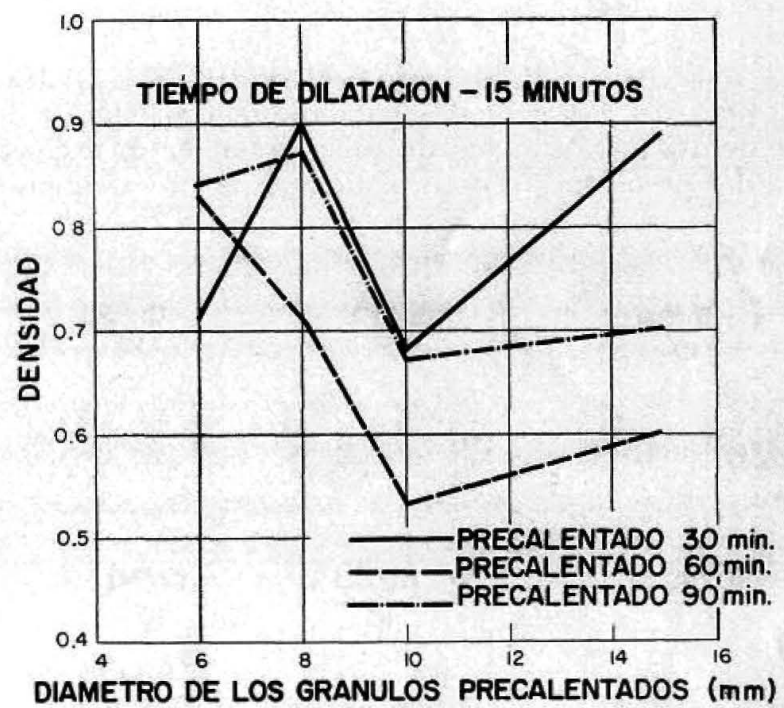

Fig. 4. Efecto del tiempo de precalentamiento sobre la densidad de gránulos de distintos tamaños sinterizados durante 15 minutos.

\section{Resulfados y discusión}

\section{Precalentamiento y golpe de fuego (Dilatación)}

Después del tratamiento o precalentamiento a $550^{\circ} \mathrm{C}$, tres de cada grupo de nódulos ya fríos se seccionaron por un plano diametral por desgaste; se vio que presentaban un corazón negro de inquemados y una pared circundante de color pardo pálido. El diámetro de la zona negra de inquemados en relación con el diámetro exterior y el tiempo de precalentamiento se muestran en las figuras 1 y 2 , respectivamente. Como era de esperar, la profundidad de la zona de oxidación completa aumenta con el tiempo de cocción y es independiente del tamaño del nódulo.

Aunque las curvas de las dos arcillas son similares, no coinciden. Esto resulta del estado en que se presenta el carbón, así como de la porosidad de las muestras. Los nódulos de la arcilla de Manastir precalentados a $550^{\circ} \mathrm{C}$ tienen una porosidad media de $31,5 \%$, mientras que los de la de Orrville la tienen del $28,2 \%$. 


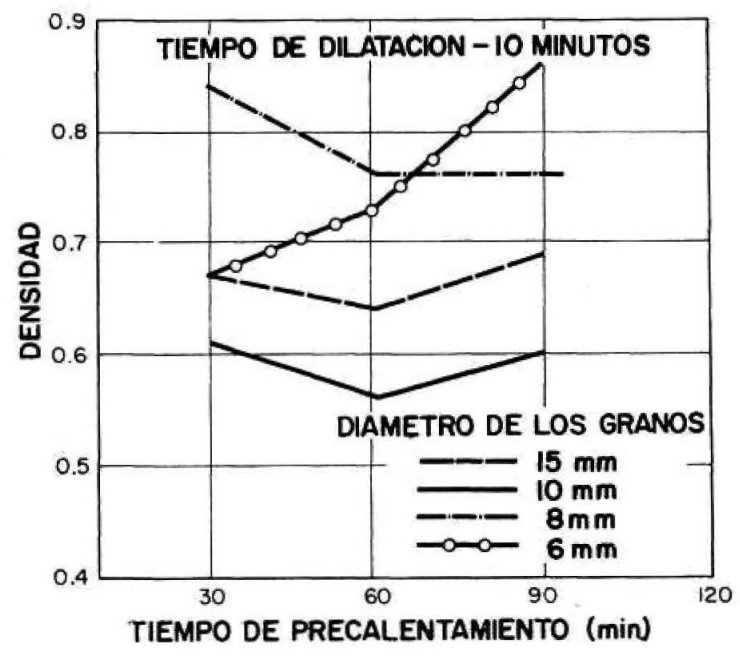

Fig. 5. Dependencia de la densidad del tiempo de precalentamiento para gránulos de diferentes tamaños dílatados durante 10 minutos.

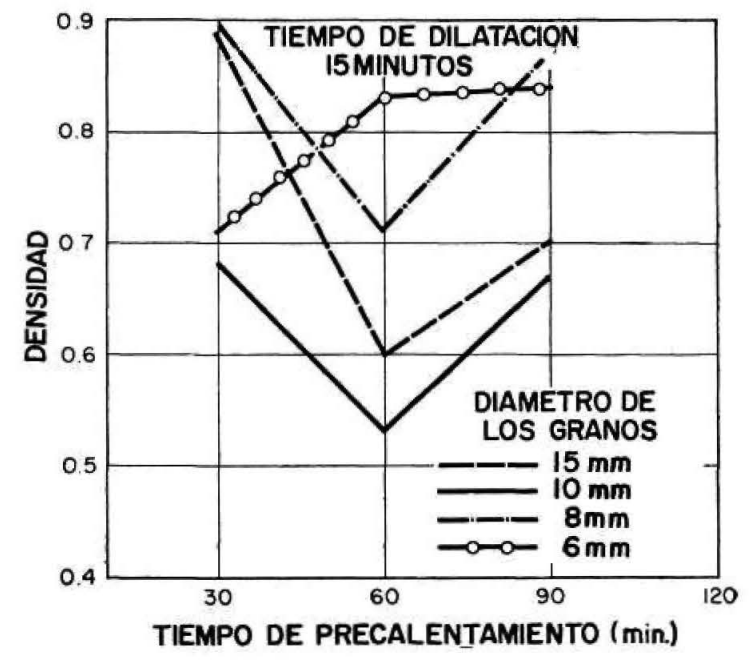

Fig. 6. Dependencia de la densidad del tiempo de precalentamiento para diferentes tamaños de gránulos dilatados durante 15 minutos.

El peso específico de las muestras de arcilla dilatada se representa en función del diámetro después de precalentadas para diferentes tiempos de precalentamiento; las figuras 3 y 4 muestran las de 10 y 15 minutos de precalentamiento, respectivamente. Las figuras 5 y 6 muestran la dependencia del peso específico en el tiempo de precalentamiento para diferentes tamaños y tiempos de dilatación.

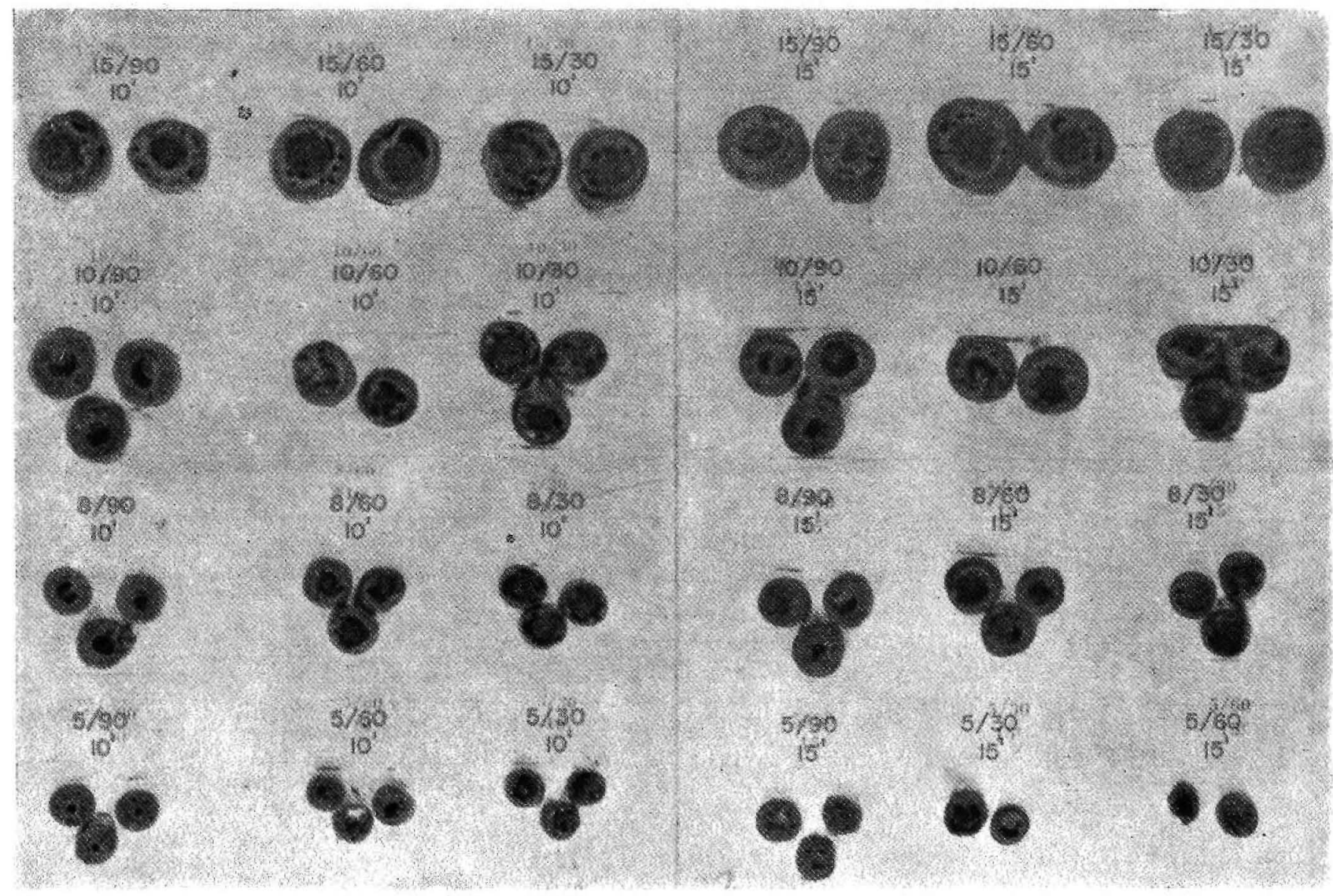

Fig. 7. Corte diametral de gránulos cocidos. Los números se refieren al tamaño del nódulo, al tiempo de precalentamiento $y$ al tiempo de cocción instantánea, respectivamente. 
La figura 5 es de 10 minutos de dilatación, y la figura 6 , de 15 minutos de dilatación. Las secciones de los nódulos dilatados se representan en la figura 7. Para cada tamaño de gránulo hay un tiempo particular de precalentamiento y dilatación que producen el mínimo de peso específico.

Todas las bolas de las que se ha eliminado el corazón negruzco durante el precalentamiento produjeron una estructura vesicular uniforme, tal como es común en los áridos ligeros «standard». Cuando las bolas precalentadas contenían un núcleo rico en carbón se produce una estructura no homogénea. El examen de la figura 7 indica una relación óptima entre el tamaño del núcleo y el diámetro exterior de la bola. Esta relación fue, aproximadamente, de 1 a 3 . De este modo se producía un gránulo después de dilatado, con una capa exterior densa y una cavidad central amplia y única. En la sección de estos gránulos se observa la pared exterior formada por un material impermeable o ligeramente permeable con una capa vítrea porosa en su capa interna. La porción central de la bola, cuyo tamaño ha sido función de las dimensiones del corazón original rico en carbón, consiste, principalmente, en una amplia cavidad con pequeñas cantidades de material vítreo en forma de vesículas irregulares (véase fig. 8).

Cuando la relación original entre el tamaño del núcleo y el diámetro exterior excede de 1 a 3 , la parte interna retiene un remanente del material rico en carbón del núcleo original, separado del anillo exterior por cavidades semicontinuas. Cuando la relación original es mucho menos de 1 a 3 , se forma una cavidad central única relativamente pequeña. Estas relaciones pueden observarse en la figura 7 .

\section{Desarrollo de la cavidad}

La estructura heterogénea formada al calentar rápidamente las bolas con núcleo rico en carbón, después de precalentadas, es el resultado de las diferencias en composicićn, temperatura y atmósfera en el interior de las mismas. La ausencia de materia orgánica en las paredes es solamente una de las diferencias entre las porciones interior y exterior. La de pérdida de los álcalis en la capa exterior por efecto del precalentado se ve comparando el contenido de álcalis entre el núcleo negro y la capa exterior después del tratamiento a $1.270^{\circ} \mathrm{C}$ (ver tabla II, núme$\operatorname{ros} 1,2$ y 3 ).

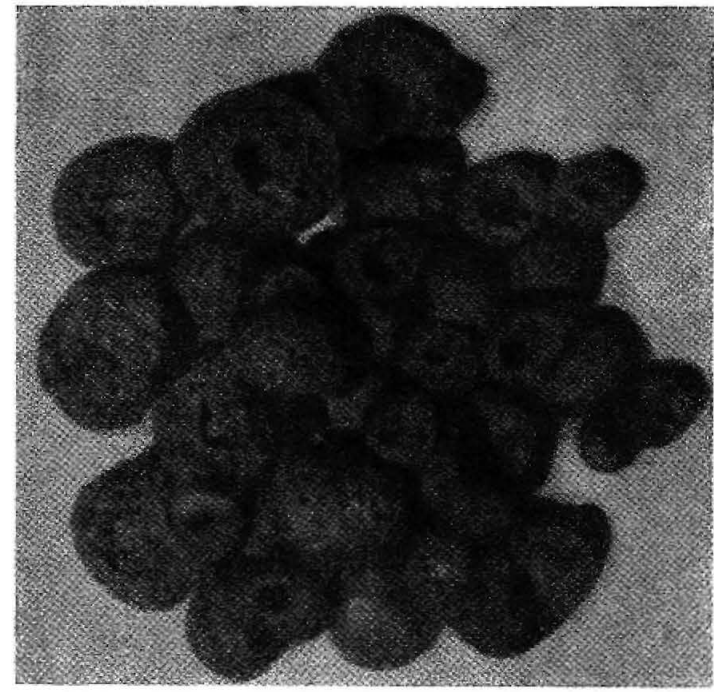

Fig. 8. Nódulos ideales con relación núcleo a diámetro exterior de $1 / 3$.

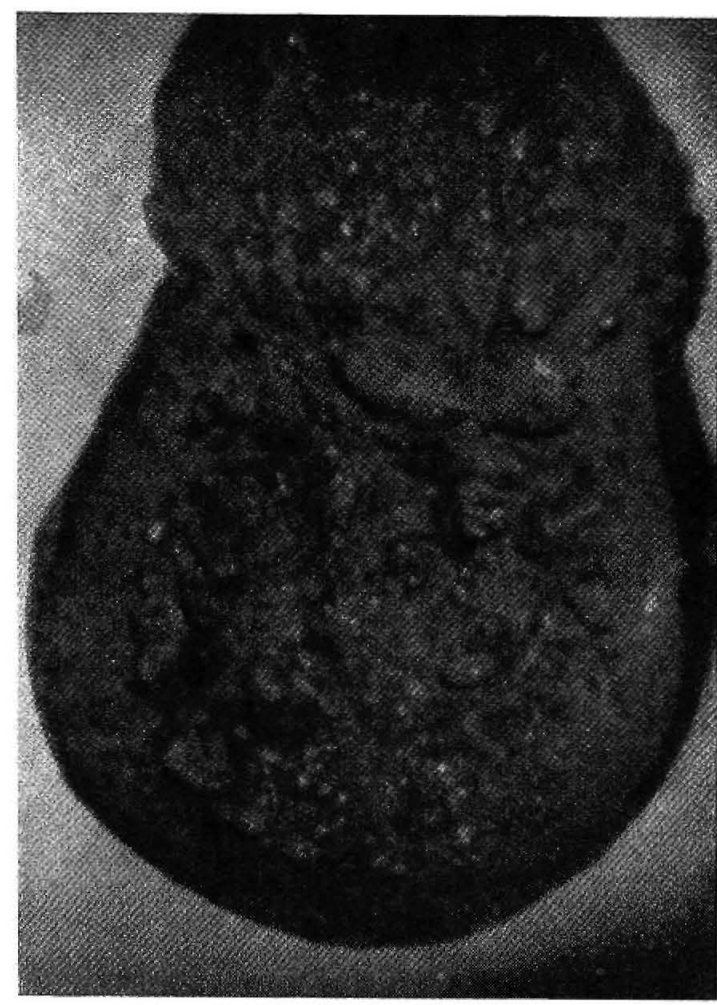

Fig. 9. Extrusión del material vítreo central a través de la pared exterior de un nódulo $(\times 7)$. 


\section{Tempo de precalentamionfo}

La influencia del tiempo de precalentado sobre las variaciones de composición, se describe también en la tabla II. Nódulos de $8 \mathrm{~mm}$ se calentaron a distintos intervalos de tiempo, desde $500^{\circ}$ a $900^{\circ} \mathrm{C}$ y desde $550^{\circ}$ a $1.270^{\circ} \mathrm{C}$. La variación en esperar que tambiér disminuyera la cantidad de 5 y 6. Estos datos indican que un incremento en el tiempo de precalentado disminuye la cantidad de azufre que permanece en la muestra. Era de contenido de azufre puede verse en los números 4, otros constituyentes volátiles; este efecto puede observarse en el pequeño grado de hinchamiento ocurrido en las muestras que han sido precalentadas durante mucho tiempo.

TABLA II.-Cambios en la composictón durante el precalentamiento.

\begin{tabular}{clcc} 
Número & \multicolumn{1}{c}{ M U E s T R A } & $\begin{array}{c}\text { Alcails } \\
(\%)\end{array}$ & $\begin{array}{c}\text { Aqufre total } \\
(\%)\end{array}$ \\
1 & Corazón negro, después de precalentada a $550^{\circ} \mathrm{C}$ & $\mathbf{3 , 7 6}$ & $\mathbf{1 , 7 8}$ \\
2 & Corazón negro, después de calentar a $1.270^{\circ} \mathrm{C}$ & 4,07 & 1,87 \\
3 & Corteza exterior, después de $1.270^{\circ} \mathrm{C}$ & $\mathbf{3 , 7 9}$ & - \\
4 & Gránulos calentados a $500^{\circ}-900^{\circ} \mathrm{C}$ durante una hora & - & 0,95 \\
5 & Gránulos calentados a $500^{\circ}-900^{\circ} \mathrm{C}$ durante dos horas & - & 0,85 \\
6 & Gránulos precalentados a $550^{\circ} \mathrm{C}$ pulverizados y calen- & - & 1,01
\end{tabular}

Todas las muestras procedentes de gránulos de $8 \mathrm{~mm}$ con arcilla de Manastir.

Cuando, por el contrario, el periodo precalentado es demasiado corto, la capa exterior que se forma al aplicar las altas temperaturas resulta de poco espesor. En este caso la presión de los gases interiores puede producir la rotura de esta capa y la salida al exterior del material en estado pastoso (fig. 9).

\section{Tamafio de los nódulos}

La cantidad de volátiles retenidos en el nódulo se relacionó con su tamaño, así como con el tỉempo de precalentamiento. Los gránulos de 4,5,6 y $7,5 \mathrm{~mm}$ de diámetro hechos de mezclas sintéticas que contenían $92,4 \%$ de arcilla de Orrville, $1,8 \%$ de tartrato sćdico potásico, $0,3 \%$ de sulfato sódico y $5,5 \%$ negro de humo se precalentaron durante 90 minutos a $550^{\circ} \mathrm{C}$ para eliminar completamente el carbón. Seis nódulos de cada tamaño se calentaron durante 15 minutos a $1.200^{\circ} \mathrm{C}$. El pesó especf́fico de estas bolas puede verse en la tabla III. Con un tiempo y una temperatura constantes de precalentado, las bolas más pequeñas pierden una cantidad relativamente grande de volátiles como se evidencia por su mayor peso específico.

\section{Reaceiones fermoqufinices}

Las reacciones de hinchamiento que tienen lugar en la capa exterior (o muestras que no contienen corazón interior) están bien estudiadas por otros investigadores (1-7).
TABLA III.-Densidad de los gránulos precalentados a $550^{\circ} \mathrm{C}$ durante 90 minutos y dilatados a $1.200^{\circ} \mathrm{C}$ durante 15 minatos.

$\begin{array}{cc}\text { Diámelro } \begin{array}{c}\text { de los gránulos } \\ (\mathrm{mm})\end{array} & \text { Densidad después de dilatados } \\ 4,5 & 0,91 \\ 6,0 & 0,86 \\ 7,5 & 0.71\end{array}$


La formación, sin embargo, de una simple cavidad es el resultado de procesos adicionales que tienen lugar en un complejo sistema heterogéneo. Estos se pueden resumir como sigue:

a) El gas que se desprende y se acumula entre el corazón y la pared exterior.

b) La vitrificación en esta región debida a la formación de ferrosilicatos, la presencia de gas, y el aumento de la presión gaseosa; agua combinada remanente procedente de las micas o materia orgánica que posiblemente acelera la velocidad de fusión.

c) Expansión y formación de la cavidad central por efecto del aumento de presión, reblandecimiento de las capas exteriores y la influencia corrosiva del vidrio fundido.

El orden de sucesión de estos cambios puede explicarse considerando las reacciones que tienen lugar en el núcleo (11); estas reacciones no solamente se relacionan entre sí, sino que también con la cantidad de vidrio fundido. Hay que pensar que en un sistema tan complejo, no todas las reacciones se conocen; en lo que sigue se puede dar una idea parcial del proceso:

El carbón se oxida parcialmente formando $\mathrm{CO}$ por la reacción:

$$
2 \mathrm{C}+\mathrm{O}_{2} \rightarrow 2 \mathrm{CO}
$$

El sulfato sódico se reduce a sulfuro y carbón:

$$
\mathrm{SO}_{4} \mathrm{Na}_{2}+4 \mathrm{C} \rightarrow \mathrm{SNa}_{2}+4 \mathrm{CO}
$$

El sulfuro sódico formado en la reacción [2] reacciona, a su vez, con la silice formada por descomposición de los minerales arcillosos en presencia del sulfato sódico:

$$
\mathrm{SNa}_{2}+3 \mathrm{SO}_{4} \mathrm{Na}_{3}+4 \mathrm{SiO}_{2} \rightarrow 4 \mathrm{SiO}_{3} \mathrm{Na}_{2}+4 \mathrm{SO}_{2}
$$

Parte del sulfato sódico puede reaccionar con la sílice libre según las siguientes reacciones:

$$
\begin{gathered}
2 \mathrm{SO}_{4} \mathrm{Na}_{2} \rightarrow 2 \mathrm{SO}_{3} \mathrm{Na}_{2}+\mathrm{O}_{2} \\
\mathrm{SO}_{3} \mathrm{Na}_{2}+\mathrm{SiO}_{2} \rightarrow \mathrm{SiO}_{3} \mathrm{Na}_{2}+\mathrm{SO}_{2}
\end{gathered}
$$

El trióxido de azufre formado en las reacciones [4] y [5], se disociaría según la reacción:

$$
2 \mathrm{SO}_{3} \rightleftharpoons 2 \mathrm{SO}_{2}+\mathrm{O}_{2}
$$

El óxido de hierro se descompone dejando oxígeno libre que se combinaría con el carbón, según la reacción [1], para formar $\mathrm{CO}$ adicional:

$$
6 \mathrm{Fe}_{2} \mathrm{O}_{2} \rightarrow 4 \mathrm{Fe}_{3} \mathrm{O}_{4}+\mathrm{O}_{2}
$$

\section{Composiclón y desprendimiento de los gases}

La composición y cantidad de los gases que producen el hinchamiento después del precalentado se determinó por la técnica del tubo de combustión. Los nódulos de arcilla de Manastir, precalentados hasta obtener una relación núcleo/diámetro de $1: 3$, fueron finamente pulverizados y calentados a $1.270^{\circ} \mathrm{C}$ durante tres horas. Un flujo de oxígeno, a la velocidad de $200 \mathrm{~cm}^{\mathrm{s}}$ por minuto a través de los gránulos arrastraba un $2,0 \%$ de $\mathrm{SO}_{2}$ y $0,98 \%$ de $\mathrm{CO}_{n}$ o sea, en una relación de 2 a I. El contenido de agua determinado por el método del tungtato sódico fue de $2,61 \%$. 


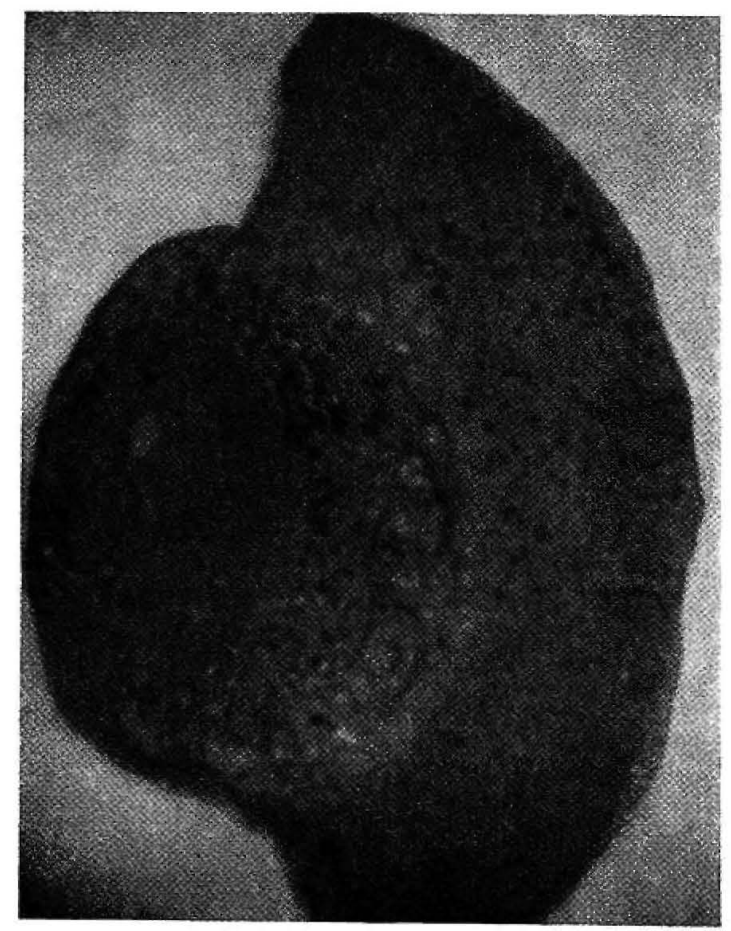

Fig. 10. Estado intermedio, en formación, de un núcleo hueco seneillo en un nódulo $(\times 7)$.

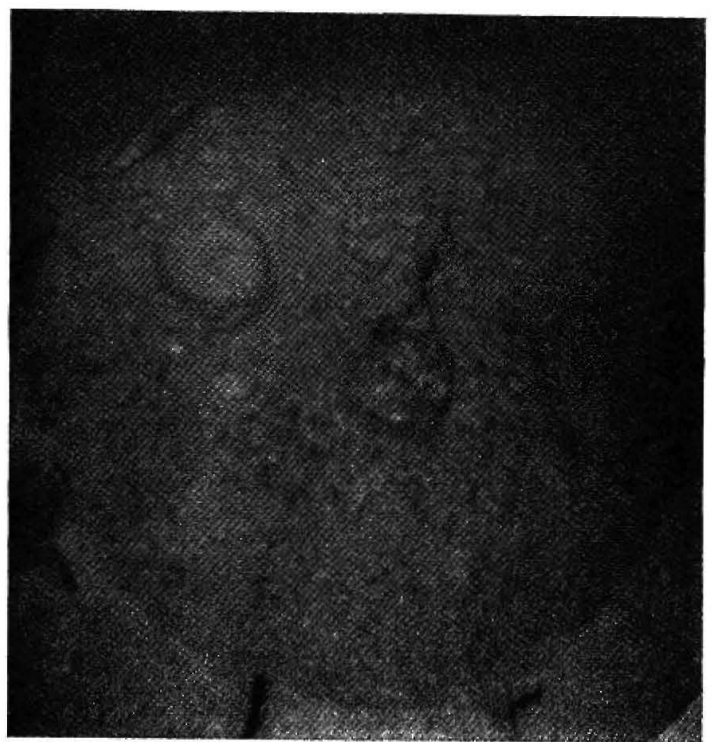

Fig. 11. Extrusión del material vitreo del núcleo en las grietas del anillo exterior de
baja de la fotografia) $(\times 7)$.
La composición del gas en los gránulos hinchados se determinó según la técnica cromatográfica de gases, tal como la describe Ehlers. $\mathrm{El}$ gas tenía $\mathrm{SO}_{2}$ y $\mathrm{CO}_{2}$ en la relación aproximada 10 a 1 . Se notó contaminación de aire por la presencia de $\mathrm{N}$ y $\mathrm{O}_{2}$ en proporciones «standard». Aunque la presencia de $\mathrm{SO}_{2}$ está de acuerdo con las condiciones de combustión, no sería razonable suponer que fuera el $\mathrm{CO}_{2}$ el gas que produce el hinchamiento primario. Durante el enfriamiento parcial de los gránulos antes del análisis cromatográfico, es probable que el aire difundido a través de los poros abiertos produzca la oxidación del $\mathrm{CO}$ primario a $\mathrm{CO}_{2}$.

Se sabe que la fusión comienza bastantes cientos de grados antes de que tenga lugar el hinchamiento. La fusión se favorece por la presencia de moscovita, la cual actúa como flujo enérgico rebajando los polieutécticos (Endell, Hoffmann y Wilm) (12). Además, los ferrosilicatos que se forman en gran cantidad durante la combustión, colaboran también a rebajar la temperatura de fusión del sistema (Lebedev) (13). Al comienzo del reblandecimiento se produce una gran cantidad de $\mathrm{CO}$ que es expulsado a través de los poros. A medida que aumenta la fase líquida, el carbón es parcialmente absorbido por el vidrio fundido y protegido de la oxidación en gran parte. La presencia de cantidades crecientes de vidrio no retardan la descomposición de los sulfatos, los cuales, en las etapas finales de la sinterización, producen una cantidad relativamente grande de gas que provoca el hinchamiento, según se ve por el análisis cromatográfico.

La formación de la gran cavidad única en el centro del gránulo es resultado de la expansión del gas sobre el vidrio viscoso que la rodea. A medida que aumenta la presión de los gases producidos por las continuas reacciones, parte de estos gases se pierden a través de los poros de la capa exterior. El movimiento hacia fuera del gas presiona sobre la delgada película de vidrio fundido de la pared interior del corazón contra la parte más resistente del anillo exterior, dando lugar así a la formación de la cavidad central única. Véanse los estados intermedios del proceso en la figura 10.

El efecto de la presión del gas sobre el origen del hueco central se estableció mediante una experiencia adicional. Muestras de arcilla de Manastir y de Orrville fueron calentadas a $400^{\circ} \mathrm{C}$ durante muchas horas para eliminar toda la materia orgánica. Los gránulos hechos con esta arcilla se envolvieron en una mezcla plástica de vidrio Pirex, caolín y arcilla de Manastir (la cual había sido tratada a $1.300^{\circ} \mathrm{C}$ y luego finamente molida). 
Calentados los gránulos así formados a $1.270^{\circ} \mathrm{C}$, se produce el agrietamiento de la capa exterior del gránulo, por cuyas grietas sale al exterior el material viscoso del interior del gránulo. Seccionados estos gránulos se aprecia el comienzo de la formación de la cavidad central única como resultado de la presión de los gases (fig. 11).

\section{$\checkmark$ Conclusiones}

Se fuede obtener un nuevo tipo de árido ligero mediante el precalentamiento controlado de arcillas dilatables. Este árido se caracteriza por una gran cavidad central y una capa exterior resistente (bolas huecas).

Los resultados obtenidos con dos arcillas ampliamente diferentes hace suponer que muchas arcillas pueden resultar aptas para este fin. Algunos materiales bajos en materia orgánica o en componentes productores de gases pueden requerir pequeños ajustes de composición.

Se puede sacar como conclusión que el carbón es significativo como productor de una atmósfera reductora en el corazón del gránulo, la cual favorece la acción fluidificante.

Los gases que producen el hinchamiento se derivan de la rotura o descomposición de los sulfatos y de la oxidación del carbón.

El pruceso de dilatactón es conocido para este tipo de materiales. Sin embargo, para obtener iguales resultados con otros materiales de distinta composicićn, sería necesario hacer experimentos adicionales para cada caso.

La relación entre tiempo de precalentamiento, tiempo y temperaturas de sinterizacićn, tamaño del gránulo, densidad obtenida, ete., ha sido discutida y estudiada y se ha determinado la relación óptima entre los tamaños del hueco interior y el tamaño del gránulo.

Se necesitan nuevas investigaciones sobre la relación entre la resistencia y las condiciones de hinchamiento, así como un método industrial de producción. Las características de ligereza de estos gránulos, unido a que su parte exterior es químicamente inerte, of rece muchas nuevas posibilidades en el uso de hormigones de áridos ligeros.

\section{bibliografía}

(1) J. E. Conley, Hewitt Wilson, T. A. Klinefelter, et al, "Production of L.jghtwelght Concrete Aggr'egates from Clays, Shales, Slates, and Other Materials", $U, S, B u r$. Mines Rept. Invest., aúm. 4401, págs, 121 (1948); Ceram. Abstr, 1949, septiembre, pág. 209 f.

(2) F. G. Jackson, "Oxidation of Ceramic Wares During Firing: II, Decomposition of Various Compounds of Iron With Sulphur Under Simulated Kiln Condition (Part I)", J. Am. Ceram. Soc., 7 [4] 223-37 (1924); "IV, Absorption of Sulphur Gases by Ferric Oxide in Clay", ibid., [7] 532-38; "V, Quantitative Study of Nature of Sulphur Evolution in Kiln-Firlng", ibia., [8] 634-42, [9] 656-62.

(3) C. R. Austin, J. L. Nunes, and J. D. Sullivan, "Basie Factors Involved in Bloating of Clays", Am. Inst. Mining \& Met. Engrs. Tech. Pub, núm. 1486; Mining Tech., 6 [4], pág. 11 (1942); Ceram. Abstr., 21 [9] 189 (1942).

(4) E. G. Ehlers, "Mechanism of Lightweight Aggregate Formation", Am. Ceram, Soc. BuL, 37 [2] 95-99 (1958)

(5) W. F. Lawrence, Jr., "Study of Effect of Various Factors on Bloating of Some Naturally Occurring and Synthesized Materials"; thesis, New York Stata Colloge of Ceramics, 1949.

(6) H. T. Stamboliev, "Production of Llghtweight Concrete Aggregate from Expanded Clay", Bilten Savezne Gradjevingke Komore, DGA 6, Belgrado, 1959.

(7) J. O, Everhart, "If Clay or Shale Makes Lightweight Aggregate", Brick \& Clay Record, 134 [5] 58-59, 86 (1959); Ceram. Abstr, 1960, noviembre, pág. $257 f$.

(8) A. H. M. Andreasen, "Erfahrungen mit der Feinheitsanalyse von technischen Stauben", Tagung des Fachausschusses für Staubtechnik in Verein Deutscher Ing, octubre 1950, Karlsruhe.

(9) H, H. Murray, "Genesis of Clay Minerais in Some Pennsylvanlan Shales of Indiana and Illinois", paginas 47-67 in Clays and Clay Minerals-Proceedings of Second National Conference on Clays and Clay Minerals (1953) (edited by Ada Swineford and Norman Plummer); Natl. Research Council, Natl, Acad. Sci (U. S.) Publ., número 327, pág. 498 (1954); Ceram. Abstr, 1956, octubre, päg. $223 f$.

(10) J. O. Everhart, E. G. Ehiers, J. E. Johnson, and J. H. Richardson, "Study of Lightweight Aggregates", Ohio State Untv. Eng. Expt. Sta. Bull, núm. 848, päg. 69 (1958).

(11) Paul Niggli, "Gleichgewichtserscheinungen zwischen Alkalicarbonaten und Kieselsëure" (Equilibrium Reactions Between Alkali Carbonates and sillea), Z. anorg. u. allgem. Chem., 84, 229-72 (1914).

(12) K. Endell, U. Hoffmann, anc D. Wilm, "ttber quarz- und glimmerhaltige Tone" (Quartay and Micaceous Clays), Sprechsaal, 67, 293-95, 309-11, 325-28 (1934).

(13) P. J. Lebedev, "On Nature of Silicates and Ore Magmas", in A. G. Fersman Memorial Volume, Akademiya Nauk S. S. S. R., Moscow, 1946. 